\title{
OXIDATION AND THE EFFECTS OF HIGH TEMPERATURE EXPOSURES ON NOTCHED FATIGUE LIFE OF AN ADVANCED POWDER METALLURGY DISK SUPERALLOY
}

\author{
Chantal K. Sudbrack ${ }^{1}$, Susan L. Draper ${ }^{1}$, Timothy T. Gorman ${ }^{1,2}$, Jack Telesman ${ }^{1}$, Timothy P. Gabb ${ }^{1}$ and David R. Hull ${ }^{1}$ \\ ${ }^{1}$ NASA Glenn Research Center; 21000 Brookpark Road, Cleveland, OH 44135 USA \\ ${ }^{2}$ University of Dayton; 300 College Park, Dayton, OH 45469 USA
}

Keywords: disk, superalloys, oxidation, low cycle fatigue, environment

\begin{abstract}
Oxidation and the effects of high temperature exposures on notched fatigue life were considered for a powder metallurgy processed supersolvus heat-treated ME3 disk superalloy. The isothermal static oxidation response at $704{ }^{\circ} \mathrm{C}, 760{ }^{\circ} \mathrm{C}$, and 815 ${ }^{\circ} \mathrm{C}$ was consistent with other chromia forming nickel-based superalloys: a $\mathrm{TiO}_{2}-\mathrm{Cr}_{2} \mathrm{O}_{3}$ external oxide formed with a branched $\mathrm{Al}_{2} \mathrm{O}_{3}$ internal subscale that extended into a recrystallized $\gamma$ 'dissolution layer. These surface changes can potentially impact disk durability, making layer growth rates important. Growth of the external scales and $\gamma$ 'dissolution layers followed a cubic rate law, while $\mathrm{Al}_{2} \mathrm{O}_{3}$ subscales followed a parabolic rate law. $\mathrm{Cr}$ - rich $\mathrm{M}_{23} \mathrm{C}_{6}$ carbides at the grain boundaries dissolved to help sustain $\mathrm{Cr}_{2} \mathrm{O}_{3}$ growth to depths about 12 times thicker than the scale.
\end{abstract}

The effect of prior exposures was examined through notched low cycle fatigue tests performed to failure in air at $704{ }^{\circ} \mathrm{C}$. Prior exposures led to pronounced debits of up to $99 \%$ in fatigue life, where fatigue life decreased inversely with exposure time. Exposures that produced roughly equivalent $1 \mu \mathrm{m}$ thick external scales at the various isotherms showed statistically equivalent fatigue lives, establishing that surface damage drives fatigue debit, not exposure temperature. Fractographic evaluation indicated the failure mode for the pre-exposed specimens involved surface crack initiations that shifted with exposure from predominately single intergranular initiations with transgranular propagation to multi-initiations from the cracked external oxide with intergranular propagation. Weakened grain boundaries at the surface resulting from the $\mathrm{M}_{23} \mathrm{C}_{6}$ carbide dissolution are partially responsible for the intergranular cracking. Removing the scale and subscale while leaving a layer where $\mathrm{M}_{23} \mathrm{C}_{6}$ carbides were dissolved did not lead to a significant fatigue life improvement, however, also removing the $\mathrm{M}_{23} \mathrm{C}_{6}$ carbide dissolution layer led to nearly full recovery of life, with a transgranular initiation typical to that observed in unexposed specimens.

\section{Introduction}

Turbine disks are fabricated from polycrystalline $\gamma(\mathrm{fcc}) / \gamma^{\prime}\left(\mathrm{L}_{2}\right)$ phase nickel-based superalloys for strength and fatigue resistance, with grain boundary carbides and borides to improve creep rupture strength. Advances in powder metallurgy alloys have produced disks with improved properties, allowing jet engines to run hotter for increased fuel efficiency and reduced emissions. However, increased operating temperatures desired for future, more efficient engines make these alloys prone to localized hot corrosion and oxidation attack [1-3], which has the potential to limit disk durability. Service conditions for disks in some aerospace and land-based gas turbine engines can produce major cycle periods extending from minutes to hours and days. Over a disk component's life, this can produce total service times exceeding 1,000 hours for aerospace applications and 100,000 hours for land-based applications. Some of the effects of service environments can be captured by extended exposures at elevated temperatures prior to conventional $\mathrm{LCF}[4,5]$

The objective of this study was to examine oxidation at potential maximum service temperatures over extended periods, and its effects on notched fatigue life, for an advanced powder metallurgy disk superalloy ME3. Environmental attack by static oxidation of coarse-grained supersolvus heat treated ME3 was examined thoroughly at temperatures of $704{ }^{\circ} \mathrm{C}\left(1300{ }^{\circ} \mathrm{F}\right)$ to $815^{\circ} \mathrm{C}(1500$ ${ }^{\circ} \mathrm{F}$ ) for extended times. Notched fatigue specimens were exposed in air at several of these conditions. Specimens were then tested using conventional fatigue tests at $704{ }^{\circ} \mathrm{C}$. The effects of these exposures on notched fatigue life, crack initiation and propagation are discussed.

\section{Materials and Experimental Procedure}

Advanced powder metallurgy disk superalloy, ME3, also sometimes referred to as Rene 104 [6,7], was argon atomized, consolidated, hot compacted, extruded and isothermally forged into production scale disks [7,8], approximately $61 \mathrm{~cm}$ diameter with a $10 \mathrm{~cm}$ maximum bore thickness and $5 \mathrm{~cm}$ rim thickness. ME3 has a nominal composition of Ni-20.6 Co-13 Cr-3.7 Ti-3.8 Mo-3.4 Al-2.4 Ta-2.1 W- $0.9 \mathrm{Nb}$ wt. $\%$, bal. $\mathrm{Ni}$ and minor elements [9]. These disks were then supersolvus solution heat treated, and given conventional stress relief and aging heat treatments $[7,8]$. Low stress ground (RMS roughness $=\sim 1 \mu \mathrm{m}$ ) coupons and square-cross section blanks, $15 \mathrm{~mm} \times 15 \mathrm{~mm} \times 54$ $\mathrm{mm}$ in dimension, were extracted from the disk rims with comparable cooling rates.

The disk rim microstructure $[7,8]$ used to fabricate specimens consisted of a mean grain diameter that ranged at ASTM 7.1-6.8 (27.1-30.6 $\mu \mathrm{m})$ with standard deviation of ASTM 0.2-0.4 (2-4 $\mu \mathrm{m})$ and an ALA grain diameter of ASTM 3.5-3 (105-125 $\mu \mathrm{m})$, Fig. 1. The $\gamma$ '-phase consisted of cuboidal secondary precipitates (0.1-0.6 um diameter) and spherical tertiary precipitates (10-40 $\mathrm{nm}$ diameter), where measured area fractions of $\gamma^{\prime}$-phase were about 0.5 . Electron diffraction and qualitative energy dispersive $x-$ ray established that $(\mathrm{Ti}, \mathrm{Ta}, \mathrm{Nb}, \mathrm{Mo}) \mathrm{C}$ carbides $(0.15-0.70 \mu \mathrm{m})$ and $(\mathrm{Mo}, \mathrm{Cr}, \mathrm{W})_{3} \mathrm{~B}_{2}$ borides $(0.4-1.0 \mu \mathrm{m})$ reside mostly within the grains, while smaller $(\mathrm{Cr}, \mathrm{Mo}, \mathrm{W})_{23} \mathrm{C}_{6}$ carbides $(<0.15 \mu \mathrm{m})$ ornament the grain boundaries. Also, a small fraction of $\mathrm{ZrO}_{2}$ oxides and $\mathrm{Al}_{2} \mathrm{O}_{3}$ oxides were observed within the grains. 


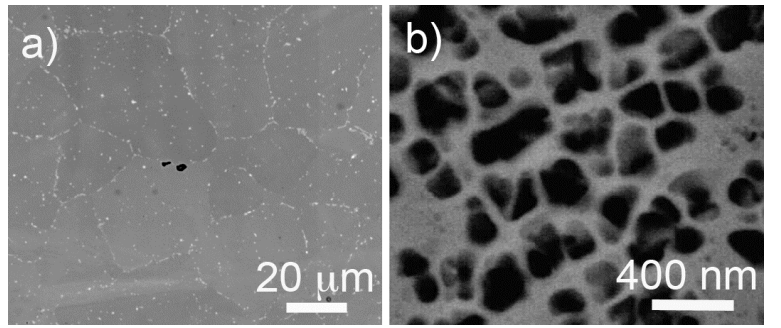

Fig. 1. Representative bulk microstructures of ME3 specimens showing a) grain structure and boride / carbide distribution (light contrast) b) secondary and tertiary $\gamma$ ' precipitates (dark contrast).

Coupon sections $(1.66 \mathrm{~cm} \times 1.05 \mathrm{~cm} \times 0.3125 \mathrm{~cm})$ were canted against the edge of a ceramic boat and oxidized statically in air at $704 \pm 3{ }^{\circ} \mathrm{C}, 760 \pm 3{ }^{\circ} \mathrm{C}, 815 \pm 3{ }^{\circ} \mathrm{C}$ for $10 \mathrm{~h}, 100 \mathrm{~h}, 440 \mathrm{~h}, 1,010 \mathrm{~h}$ and $2,020 \mathrm{~h}$ in a conventional resistance furnace, then air cooled. Surfaces and cross sections of the oxidized coupons were examined using optical microcopy, scanning electron microscopy (SEM), a JEOL JXA-8200 scanning electron microprobe and Carl Zeiss Auriga Crossbeam Workstation (FIB-SEM). To preserve the oxide surface during metallographic cross section preparation, sections were $\mathrm{Au} / \mathrm{Pd}$ sputtered for $360 \mathrm{~s}$ then electroplated with $\mathrm{Ni}$, using a Watts solution [10] modified to include $1 \mathrm{~mL}$ of Aerosol solution (a.k.a. sodium dioctyl sulfosuccinate) per $1 \mathrm{~L}$ of deionized water.

Cylindrical notched low cycle fatigue (NLCF) specimens with a circumferential notch having a $0.813 \mathrm{~mm}$ radius of curvature and $5.08 \mathrm{~mm}$ gage diameter were fabricated by an external vendor to an elastic stress concentration of $\mathrm{K}_{\mathrm{t}}=2$. NLCF specimen notches were polished longitudinally to less than $0.41 \mu \mathrm{m}$ RMS roughness. Fully machined NLCF specimens and two blanks were exposed at high temperature under ambient air in a conventional resistance furnace by: i) equilibrating at $400{ }^{\circ} \mathrm{C}$ for $10 \mathrm{~h}$ or longer, ii) ramp heating in $0.5 \mathrm{~h}$ to $25{ }^{\circ} \mathrm{C}$ below the exposure temperatures, iii) ramp heating in $0.5 \mathrm{~h}$ to the exposure temperatures, iv) holding isothermally up to $2,020 \mathrm{~h}$. Specimens and blanks were then removed from the furnace and placed on a ceramic brick to air cool. For exposures in vacuum, specimens were wrapped with two layers of Ta foil to getter oxidation during exposure. A similar temperature profile to the air exposures were used for the vacuum exposures, except specimens were furnace cooled. Several specimens pre-exposed at $815^{\circ} \mathrm{C}$ for $2,020 \mathrm{~h}$ were repolished to remove $19-23 \mu \mathrm{m}$ and $48-52 \mu \mathrm{m}$ from the notch radius by the same external vendor. Notch surfaces of fatigue specimens were imaged with SEM prior to NLCF testing.

Notched fatigue tests at $704{ }^{\circ} \mathrm{C}$ were performed to failure using closed-loop servo-hydraulic testing machines. The load control testing used a triangular waveform having a maximum net section stress of $855 \mathrm{MPa}(124 \mathrm{ksi})$, a stress ratio $\left(\mathrm{R}(\sigma)=\sigma_{\max } / \sigma_{\min }\right)$ of 0.05 , and a frequency of $0.333 \mathrm{~Hz}$. Fracture surfaces of fatigue specimens were evaluated by SEM. Crack initiation origins and crack propagation failure modes were identified and characterized. Longitudinal metallographic cross sections oriented parallel to the loading axis were taken from the gage sections in the plane of the primary crack front, $\pm 20 \mu \mathrm{m}$, to investigate secondary cracking and other damage.

A goodness of fit parameter Q based on the incomplete gamma function was used to estimate the quality of the data fitting. All fits presented had values of $\mathrm{Q}>0.1$, indicating the models used had a strong goodness of fit. The error in data fitting is the standard deviation of Gaussian distribution, determined by the diagonal element of the covariance matrix.

\section{Results and Discussion}

ME3 static oxidation of flat coupons

Our oxidation studies of ME3 coupons focused on the static isothermal response at $704{ }^{\circ} \mathrm{C}, 760{ }^{\circ} \mathrm{C}$ and $815^{\circ} \mathrm{C}$. The oxidation behavior was found for the most part to be consistent with other high $\mathrm{Cr}$ content Ni-based disk alloys, Waspaloy, Astroloy, Udimet 720, RR1000 [1-4], where the external scale consisted of continuous $\mathrm{Cr}_{2} \mathrm{O}_{3}$ (a.k.a. esckolite) and faceted $\mathrm{TiO}_{2}$ (a.k.a. rutile) grains (Fig. 2). The $\mathrm{TiO}_{2}$ grains, which may spall, were primarily located at the exposed surface and become more abundant with exposure time.

Cross section evaluation uncovered that complex near-surface damage results from these exposures. An internal subscale of branched $\mathrm{Al}_{2} \mathrm{O}_{3}$ fingers was evident beneath the $\mathrm{Cr}_{2} \mathrm{O}_{3}-\mathrm{TiO}_{2}$ scale in $\mathrm{ME} 3$, even at the shortest exposures. These $\mathrm{Al}_{2} \mathrm{O}_{3}$ fingers extended into a volume of the alloy where $\gamma^{\prime}$-precipitates have been dissolved by $\mathrm{Al}$ depletion. As shown for the $815^{\circ} \mathrm{C}$ for 440 $\mathrm{h}$ exposure in Fig. 2, the precipitate-free volume is recrystallized and contains isolated, spherical voids that were about $1 \mu \mathrm{m}$ in diameter at the near-surface grain boundaries. These voids have been attributed by others to result from an accumulation of vacancies left by $\mathrm{Cr}$ and $\mathrm{Ti}$ diffusion [2]. Light contrast grains, present in the oxide, contained no $\mathrm{O}$ and were $\mathrm{Ni}$ and $\mathrm{Co}$ rich, suggesting these are recrystallized grains from the alloy which were captured during oxide growth. A sub-micron thick sub-layer of $(\mathrm{Ta}, \mathrm{Cr}) \mathrm{O}_{2}$, which images brightly and has a rutile compound structure, was found to line the oxide/metal interface. $(\mathrm{Ta}, \mathrm{Cr}) \mathrm{O}_{2}$ also sometimes wets the $\mathrm{Al}_{2} \mathrm{O}_{3}$ fingers.

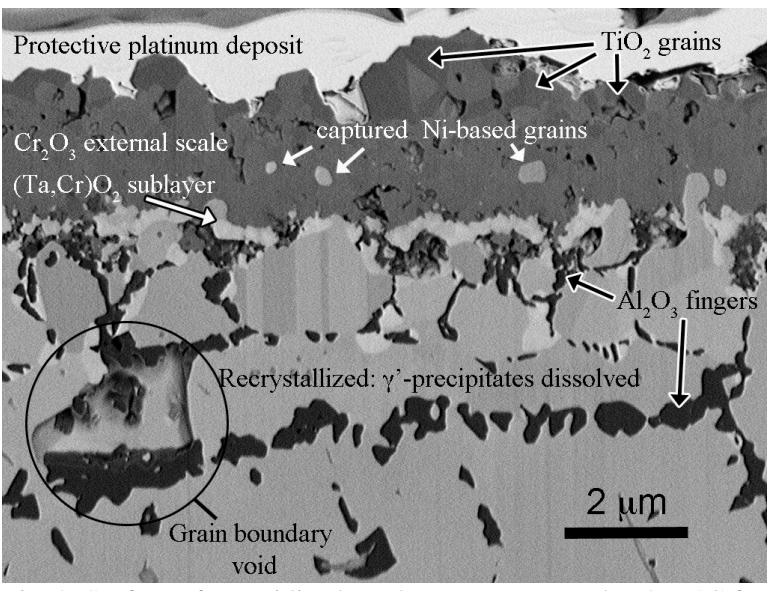

Fig. 2. Surface of an oxidized ME3 coupon, exposed at $815^{\circ} \mathrm{C}$ for $440 \mathrm{~h}$, acquired while serial sectioning with the focused ion beam at $2 \mathrm{kV}$ using the EsB in-lens back-scattered SEM detector.

Microprobe evaluation revealed that the oxidation process leads to chemical changes that extend beyond the near surface attack, Fig. 3. In the bulk, the $\mathrm{M}_{23} \mathrm{C}_{6}$ carbides in the grain boundaries appear to be enriched in $\mathrm{Cr}$, Mo, Co, which is consistent with observations that $\mathrm{Co}$ is a major component in $\mathrm{M}_{23} \mathrm{C}_{6}$ carbides in a similar disk alloy, LSHR [11]. Towards the oxidized surface, the ME3 grain boundaries are depleted in $\mathrm{Cr}$, $\mathrm{Mo}, \mathrm{Co}$ and enriched in $\mathrm{Ni}$ relative to bulk grain boundaries as shown in Fig. 3a for a 

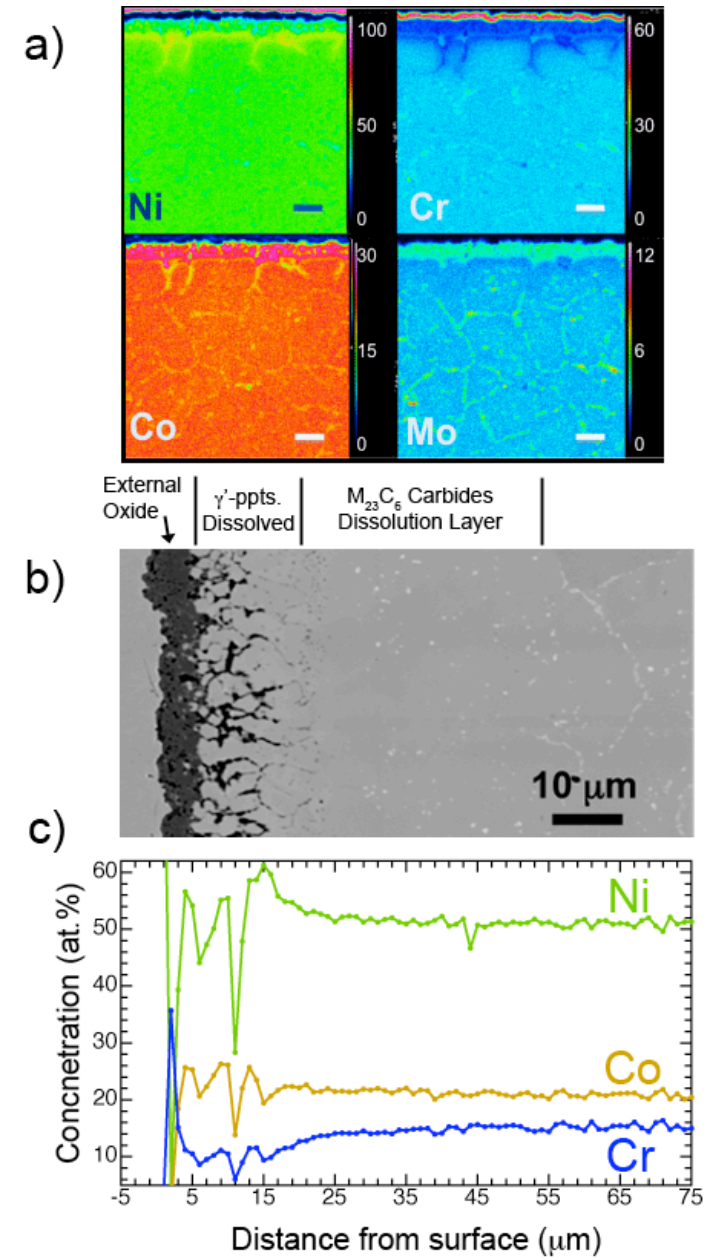

Fig. 3. Microprobe results for the surface of an oxidized ME3 coupon, exposed at $815{ }^{\circ} \mathrm{C}$ for $2,020 \mathrm{~h}$, shows: a) a subset of chemical maps with $20 \mu \mathrm{m}$ scale bar, b) dissolution of brightly imaging carbides in a back-scattered SEM image and c) representative line concentrations profiles for $\mathrm{Ni}, \mathrm{Co}, \mathrm{Cr}$.

specimen exposed at $815{ }^{\circ} \mathrm{C}$ at $2,020 \mathrm{~h}$. Fig. 3b shows that the volume adjacent to the oxide is depleted in carbides/borides, which image brightly in back-scattered SEM due to their high refractory content. This $\mathrm{M}_{23} \mathrm{C}_{6}$ dissolution is accompanied by gradients in both $\mathrm{Ni}$ and $\mathrm{Cr}$, Fig. $3 \mathrm{c}$. The $\mathrm{M}_{23} \mathrm{C}_{6}$ carbide liquation temperature for ME3 in equilibrium was predicted to be $880.7^{\circ} \mathrm{C}$, which is near the exposure temperatures utilized in this study, using microstructural modeling package JMatPro-Ni 6.0. Between $25 \mu \mathrm{m}$ and $50 \mu \mathrm{m}$ depths, there is still a good number of carbides/borides present. Further in, at roughly $50 \mu \mathrm{m}$ depth, there is a clear transition from no/limited $\mathrm{M}_{23} \mathrm{C}_{6}$ coverage to full $\mathrm{M}_{23} \mathrm{C}_{6}$ coverage at the grain boundaries. Chemical mapping, Fig. 3a, shows Mo rich areas (i.e. Mo-rich minor phases) within the grains that are not rich in $\mathrm{Cr}$, which suggests that the carbides/borides present are mostly the more stable $\mathrm{MC}$ carbides and $\mathrm{M}_{3} \mathrm{~B}_{2}$ borides. For stable $\mathrm{M}_{23} \mathrm{C}_{6}$ carbides in equilibrium, the $\mathrm{Cr}$ content is nearly 2.5 times greater than the bulk concentration in at.\% [11]. Near the surface, $\mathrm{Cr}$ from $\mathrm{M}_{23} \mathrm{C}_{6}$ carbides has diffused out to help sustain the $\mathrm{Cr}_{2} \mathrm{O}_{3}$ scale growth, while $\mathrm{Mo}$ and $\mathrm{Co}$ accumulated underneath the external scale, within $\gamma^{\prime}$-dissolution layer. Furthermore, the recrystallized $\gamma^{\prime}$-dissolution layer is depleted in $\mathrm{Al}, \mathrm{Cr}, \mathrm{Ti}$, and $\mathrm{Ta}$ due to the formation of the major oxides.

A comparison of the resulting oxides for several of the coupon exposures is shown in Fig. 4. The $\gamma^{\prime}$-dissolution layer was best imaged with differential interference contrast (DIC) optical microscopy, which would resolve layer thicknesses to $1 \mu \mathrm{m}$. Even at the shortest times the external scale appeared to be continuous and fairly uniform in thickness, and $\mathrm{Al}_{2} \mathrm{O}_{3}$ fingers were present. Table I compares the measurements for the extension of carbide dissolution with those for the oxide scale thickness, alumina finger penetration and thickness of $\gamma^{\prime}$-dissolution layer at 2,020 h exposures. The $\mathrm{M}_{23} \mathrm{C}_{6}$ dissolution layers were 3 times greater than the thicknesses of the $\gamma^{\prime}$-dissolution layer (where $\mathrm{Al}_{2} \mathrm{O}_{3}$ fingers reside), which were roughly 3 times greater than the external oxide scale thicknesses. These layer dimensions are additive. For example, for the most aggressive $815^{\circ} \mathrm{C}$ at $2,020 \mathrm{~h}$ exposure imaged in Fig. 3b, a $\sim 20 \mu \mathrm{m}$ depth removal would ensure that both the external oxide and subscale would be fully removed, while a $\sim 50 \mu \mathrm{m}$ depth removal would remove material past the $\mathrm{M}_{23} \mathrm{C}_{6}$ carbide dissolution layer into the bulk alloy.

Table I. Oxide scale thickness, alumina finger penetration, $\gamma$ 'dissolution layer thickness and the extension of carbide dissolution past $\gamma^{\prime}$-dissolution at 2,020 hours with temperature.

\begin{tabular}{|c|c|c|c|c|}
\hline in $\mu \mathrm{m}$ & $\begin{array}{c}\text { Avg. Scale } \\
\text { Thickness } \\
\pm \sigma^{1}\end{array}$ & $\begin{array}{c}\text { Avg. } \mathrm{Al}_{2} \mathrm{O}_{3} \\
\text { Penetration } \\
\pm \sigma^{1}\end{array}$ & $\begin{array}{c}\text { Avg. } \gamma^{\prime}-\text { ppts. } \\
\text { Dissolution } \\
\pm \sigma^{1}\end{array}$ & $\begin{array}{c}\text { Mean } \mathrm{M}_{23} \mathrm{C}_{6} \\
\text { Dissolution }^{2} \\
\pm \mathrm{SE}^{3}\end{array}$ \\
\hline $\begin{array}{c}\text { Technique } \\
\text { (\# values) }\end{array}$ & $\begin{array}{c}\text { SEM } \\
(3840)\end{array}$ & $\begin{array}{c}\text { SEM } \\
(24)\end{array}$ & $\begin{array}{c}\text { Optical DIC } \\
(24)\end{array}$ & $\begin{array}{c}\text { WDS } \\
\text { EPMA (4) }\end{array}$ \\
\hline $\begin{array}{c}\text { Values } \\
\text { Distributed }\end{array}$ & $\begin{array}{c}\text { Log } \\
\text { Normal }\end{array}$ & Normal & Normal & - \\
\hline $\begin{array}{c}704{ }^{\circ} \mathrm{C} \\
2020 \mathrm{~h}\end{array}$ & $1.31 \pm 0.41$ & $2.97 \pm 0.78$ & $3.11 \pm 1.03$ & $9.6 \pm 2.3$ \\
\hline $\begin{array}{c}760^{\circ} \mathrm{C} \\
2020 \mathrm{~h}\end{array}$ & $1.96 \pm 0.41$ & $5.17 \pm 0.74$ & $5.80 \pm 1.27$ & $16.4 \pm 2.4$ \\
\hline $\begin{array}{c}815^{\circ} \mathrm{C} \\
2020 \mathrm{~h}\end{array}$ & $3.73 \pm 0.83$ & $9.97 \pm 1.23$ & $10.58 \pm 0.89$ & $32.6 \pm 4.2$ \\
\hline
\end{tabular}

1. $\sigma$ is the standard deviation for the fitted distribution

2. $\mathbf{M}_{23} \mathrm{C}_{6}$ dissolution is measured to extend from the bottom of $\gamma^{\prime}$ dissolution layer to the far-field saturation where the $\mathrm{Cr}$ gradient subsides. 3. $\mathrm{SE}$ is the standard error of the mean value

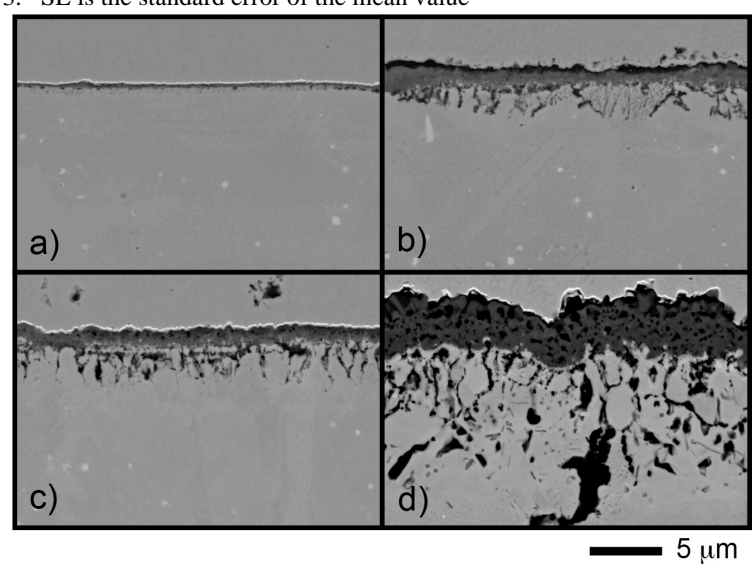

Fig. 4. Surfaces of oxidized ME3 coupons, exposed at a) $704{ }^{\circ} \mathrm{C}$ for $100 \mathrm{~h}$, b) $704^{\circ} \mathrm{C}$ for $2,020 \mathrm{~h}$, c) $815^{\circ} \mathrm{C}$ for $100 \mathrm{~h}$ and d) $815^{\circ} \mathrm{C}$ for $2,020 \mathrm{~h}$. 
The thickness of external scale, the depth of $\mathrm{Al}_{2} \mathrm{O}_{3}$ finger penetration, and the thickness of $\gamma^{\prime}$-dissolution layer were consistently measured on the left-side, middle and right-side of Ni-plated cross sections for all exposures. The standard errors were determined by the variation in average values of the three areas. Oxide scale measurements were log-normally distributed, while the finger depths and $\gamma^{\prime}$-dissolution layer thicknesses were normally distributed.

The isothermal oxidation reaction kinetics for the measured averages of all three quantities is displayed in Fig. 5. The trends

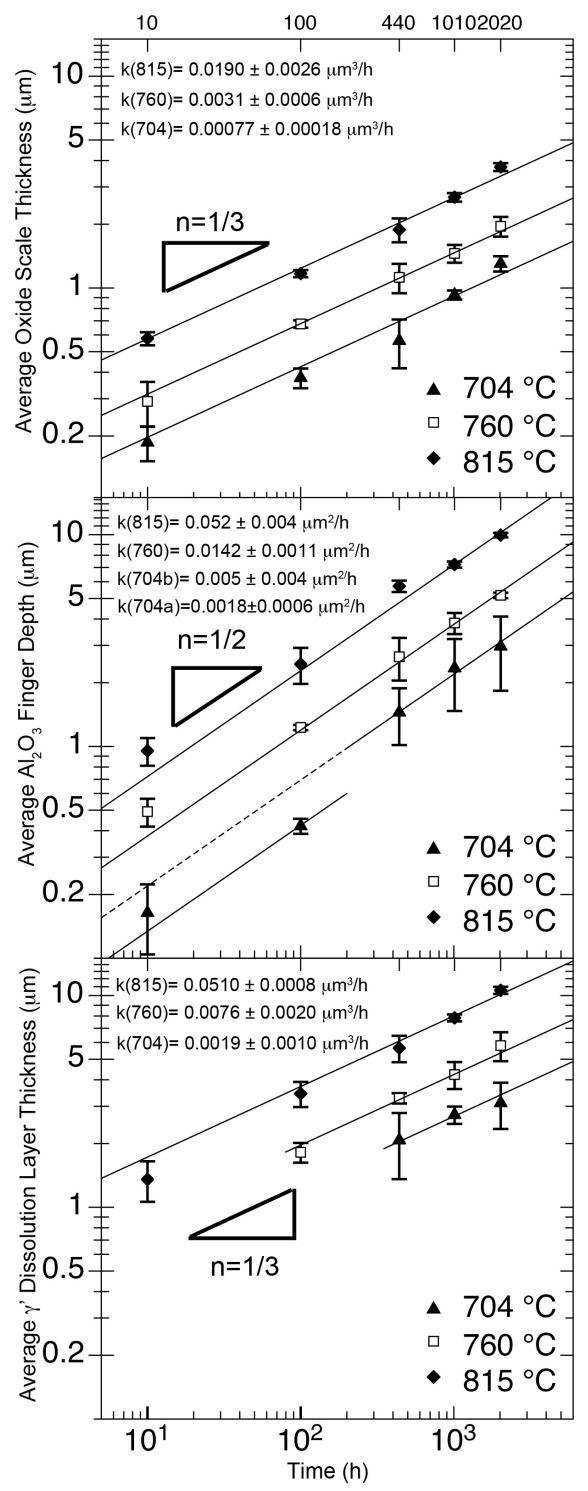

Fig. 5. The average measured growth for the external scale thickness (top), $\mathrm{Al}_{2} \mathrm{O}_{3}$ finger length (middle) and $\gamma^{\prime}$-dissolution layer thickness (bottom) for static oxidation of ME3 exposed in air at $704{ }^{\circ} \mathrm{C}, 760{ }^{\circ} \mathrm{C}$ and $815{ }^{\circ} \mathrm{C}$ up to 2,020 hours. The solid lines denote the power law fit, $y=(k \cdot t)^{n}$, while the dashed lines mark the continuation of the fit to shorter exposure times. The standard deviation of the geometric averages of the three areas is used for the measurement error. were determined by fitting the data $(y)$ with time $(t)$ to a simple power law of $y=(k \cdot t)^{n}$, where $k$ is the growth rate constant and $n$ is the temporal exponent. The kinetics for external oxide scale thickness (OST) deviated from classic parabolic growth, time $\mathrm{e}^{1 / 2}$ and followed a cubic rate law, time ${ }^{1 / 3}$, which may be attributed to significant grain growth within the $\mathrm{Cr}_{2} \mathrm{O}_{3}$ oxide [12]. In contrast, a parabolic rate law was determined for the average planar extension of the $\mathrm{Al}_{2} \mathrm{O}_{3}$ fingers (AFD) from the oxide/metal interface into the metal. The inward growth suggests that oxygen diffuses inward from the oxide/metal interface [13]. For $704{ }^{\circ} \mathrm{C}$ for $10 \mathrm{~h}$ and $100 \mathrm{~h}$ exposures, Fig. 5, the finger depths measured were noticeably smaller than the continuation of the trend from longer exposure times, likely a deviation associated with the earliest stages of $\mathrm{Al}_{2} \mathrm{O}_{3}$ growth. For these short exposures, $\gamma$ ' precipitates in the near vicinity of the forming $\mathrm{Al}_{2} \mathrm{O}_{3}$ fingers are dissolved, yet the $\gamma$ '-dissolution layer has not reached a critical thickness to recrystallize. $\mathrm{Al}_{2} \mathrm{O}_{3}$ appears to wet the oxide/metal interface as a very thin, semi-continuous layer, which is not observed for the more aggressive exposures. The $\gamma^{\prime}$-dissolution layer (GPD) kinetics mimicked the cubic rate law of the oxide scale, Fig. 5. Average thickness of the $\gamma^{\prime}$-dissolution layer was observed to be roughly 2-3 times greater than the oxide scale thicknesses.

Assuming either a cubic or parabolic rate holds, further analysis of the data in Fig. 5 is possible using an Arrhenius relationship of $k=k_{0} \exp (-Q / R T)$, where $Q$ is an activation energy for growth, $R$ is the gas constant, $T$ is the exposure temperature (in Kelvin) and $k_{0}$ is the pre-exponential factor. Plotting $\ln k$ versus $1 / T$ produced

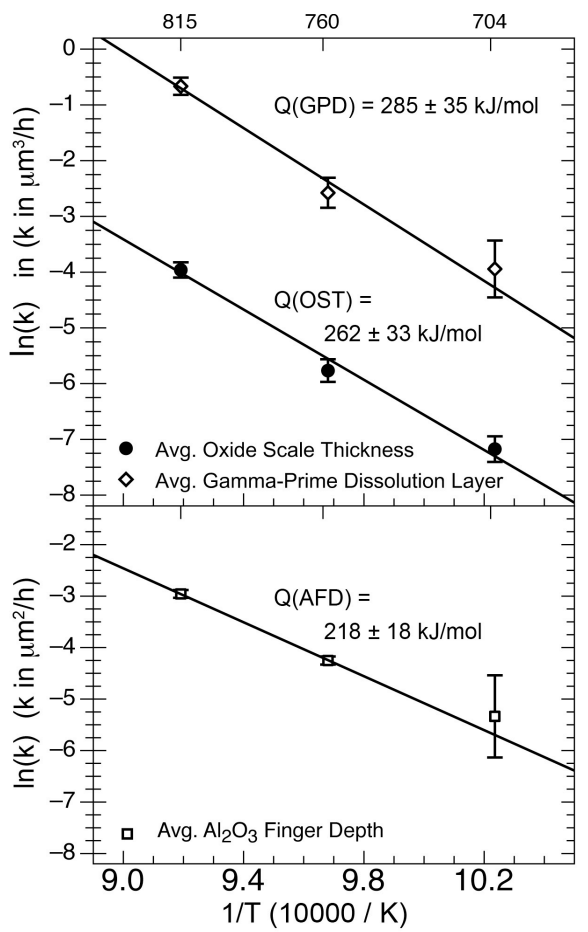

Fig. 6. The Arrhenius plots of the natural logarithm of the experimentally determined rate constants for the growth of the oxide scale thickness (OST), $\gamma^{\prime}$-dissolution layer (GPD), and $\mathrm{Al}_{2} \mathrm{O}_{3}$ finger depths (AFD) shows a linear relationship with

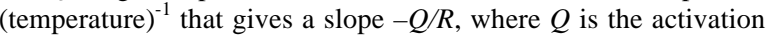
energy for growth and $R$ is the gas constant. 
straight lines with a slope of $-Q / R$, Fig. 6 . The activation energies for growth were determined to be $Q($ OST $)=262 \pm 33 \mathrm{~kJ} / \mathrm{mol}$, $Q(\mathrm{AFD})=218 \pm 18 \mathrm{~kJ} / \mathrm{mol}$, and $Q(\mathrm{GPD})=285 \pm 35 \mathrm{~kJ} / \mathrm{mol}$. There is good agreement for $Q(\mathrm{OST})$ with the literature value for $\mathrm{Cr}_{2} \mathrm{O}_{3}$ growth of $256 \mathrm{~kJ} / \mathrm{mol}$ [14], even though $\mathrm{TiO}_{2}$ grains have been included in the thickness determination.

Effect of Prior Exposure on ME3 Notched Fatigue Life at $704{ }^{\circ} \mathrm{C}$ Static oxidation ME3 tests were used as a basis for the preexposure conditions used for the NLCF testing. Short $(100 \mathrm{~h})$, mid $(440 \mathrm{~h})$ and long $(2,020 \mathrm{~h})$ exposure times at the low $\left(704{ }^{\circ} \mathrm{C}\right)$ and high $\left(815{ }^{\circ} \mathrm{C}\right)$ isotherms were selected, as well as $760{ }^{\circ} \mathrm{C}$ for 440 h. To isolate the contributions of environmental attack and heat treatment on the notched fatigue behavior, specimens pre-exposed in vacuum at $815{ }^{\circ} \mathrm{C}$ for $440 \mathrm{~h}$ and blanks machined after preexposure in air at $815^{\circ} \mathrm{C}$ for $440 \mathrm{~h}$ and $815^{\circ} \mathrm{C}$ for $2,020 \mathrm{~h}$ were tested. Lastly, $\sim 20 \mu \mathrm{m}$ and $\sim 50 \mu \mathrm{m}$ in depth was polished away from the notch radii of specimens pre-exposed at $815{ }^{\circ} \mathrm{C}$ for 2,020 $\mathrm{h}$ to fully remove material to depths past the $\mathrm{Al}_{2} \mathrm{O}_{3}$ fingers and past the $\mathrm{M}_{23} \mathrm{C}_{6}$ carbide dissolution layer.

Notch surfaces for at least one specimen for each condition were imaged with SEM prior to testing Fig. 7. As expected, no environmental attack was evident on notch surfaces of the unexposed, Fig. 7a, pre-exposed in vacuum, and machined preexposed blanks. This was also the case for pre-exposed specimens with material removed from the notch, Fig. $7 \mathrm{~g}$-h. A check of the longitudinal gage cross sections of these conditions confirmed that the repolish procedure was indeed successful in removing the targeted damage layers. With increasing temperature and time, the external oxide grains appear to grow, supporting the cubic rate law observed, and coverage becomes more uniform, Fig. 7c-f. For the $815^{\circ} \mathrm{C}$ h for $2,020 \mathrm{~h}$ exposure, Fig. $7 \mathrm{f}$, the number of faceted $\mathrm{TiO}_{2}$ grains is significant.

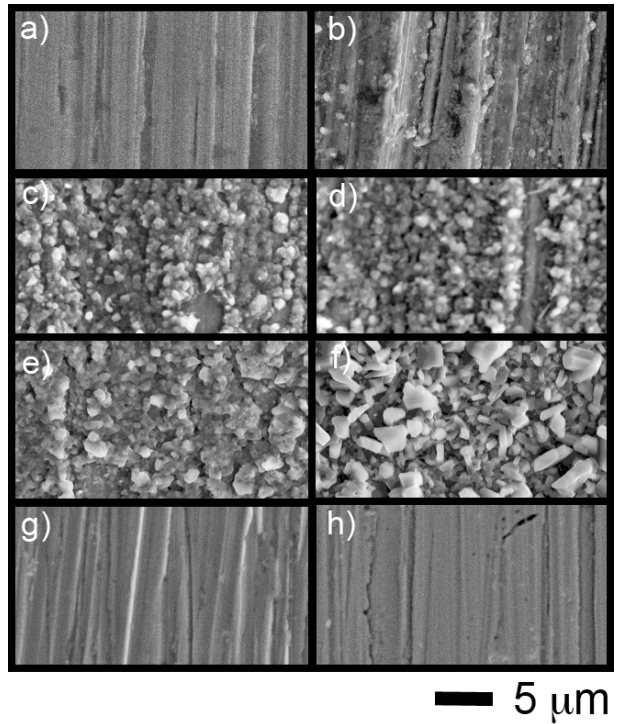

Fig 7. Notch surfaces of ME3 fatigue specimens prior to testing for conditions: a) as-machined, b) $704{ }^{\circ} \mathrm{C}$ for $100 \mathrm{~h}$, c) $704{ }^{\circ} \mathrm{C}$ for $2,020 \mathrm{~h}$, d) $760{ }^{\circ} \mathrm{C}$ for $440 \mathrm{~h}$, e) $815^{\circ} \mathrm{C}$ for $100 \mathrm{~h}$, f) $815^{\circ} \mathrm{C}$ for $2,020 \mathrm{~h}, \mathrm{~g}) 815^{\circ} \mathrm{C}$ for $2,020 \mathrm{~h}$ with $\sim 20 \mu \mathrm{m}$ removed, h) $815^{\circ} \mathrm{C}$ for $2,020 \mathrm{~h}$ with $\sim 50 \mu \mathrm{m}$ removed. Loading direction is vertical.
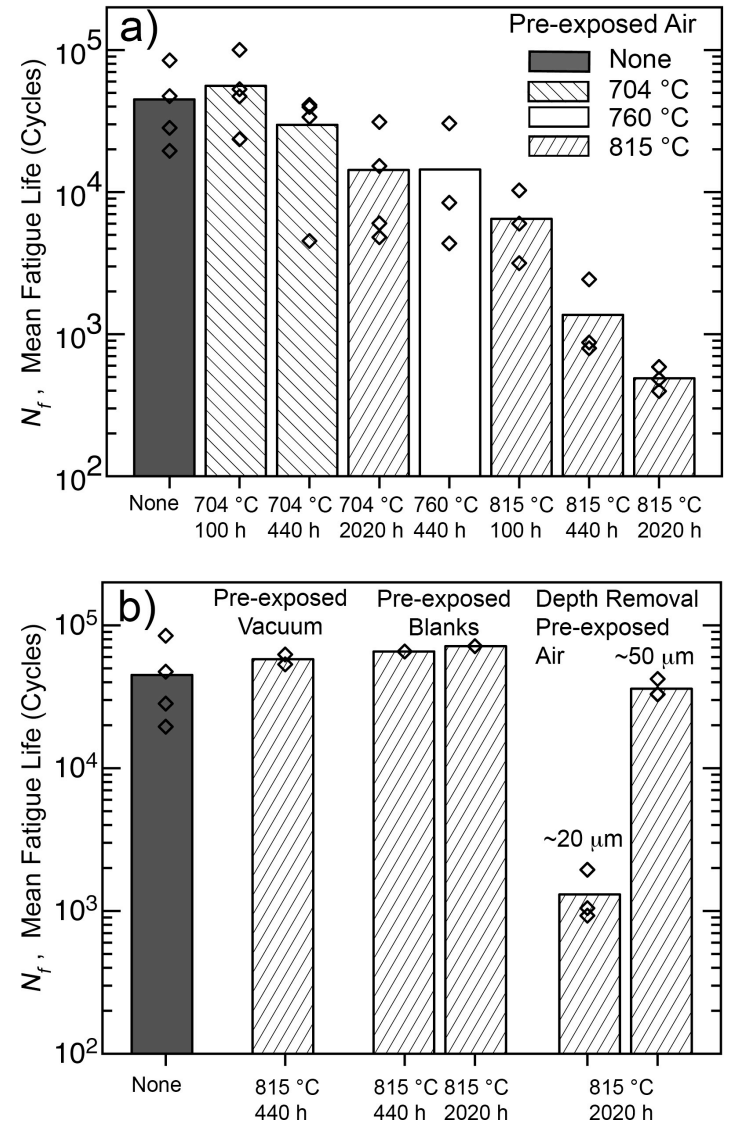

Fig. 8. Comparison of the mean notched fatigue lives at $704{ }^{\circ} \mathrm{C}$ of the unexposed ME3 specimens and ME3 specimens with a) prior exposures in air and b) alternate conditions as marked. Diamonds are each test result.

A comparison of the effects of the various pre-exposure conditions on the mean notched fatigue life $\left(N_{f}\right)$ of ME3 specimens tested at $704{ }^{\circ} \mathrm{C}$ is displayed in Fig. 8. Each test is represented by a diamond and $N_{f}$ by the bar chart. The majority of the conditions tested, including the unexposed, exhibited a scatter of about $2 \mathrm{x}-4 \mathrm{x}$ between the lowest and highest $N_{f}$. However, specimens exposed at $704{ }^{\circ} \mathrm{C}$ for $440 \mathrm{~h}, 704{ }^{\circ} \mathrm{C}$ for $2,020 \mathrm{~h}$ and at $760{ }^{\circ} \mathrm{C}$ for $440 \mathrm{~h}$ showed larger scatter.

Environmental exposures led to debits in fatigue life, which became more pronounced with increasing time and temperature, Fig. 8a. The unexposed samples had a mean fatigue life $N_{f}$ of 44,949 cycles compared to only 489 cycles for samples exposed to $815^{\circ} \mathrm{C}$ for $2020 \mathrm{~h}$, a nearly $99 \%$ debit. The $704{ }^{\circ} \mathrm{C}$ for $100 \mathrm{~h}$ exposure resulted in minor damage to the specimen surface, Fig. 8 a, not sufficient to affect the fatigue life as there was no debit in $N_{f}$. Three of the four specimens exposed at $704{ }^{\circ} \mathrm{C}$ for $440 \mathrm{~h}$ showed no significant debit, while the fourth specimen exhibited $90 \%$ lower life. As shown for coupon oxidation, Fig. 5, $704{ }^{\circ} \mathrm{C}$ for $2,020 \mathrm{~h}, 760{ }^{\circ} \mathrm{C}$ for $440 \mathrm{~h}$, and $815^{\circ} \mathrm{C}$ for $100 \mathrm{~h}$, produce roughly equivalent external scale thicknesses, $\mathrm{Al}_{2} \mathrm{O}_{3}$ finger depths and $\gamma$ '-dissolution layer thicknesses. These samples had statistically equivalent mean fatigue lives, showing the depth of the surface damage is the major driver, not exposure temperature. 


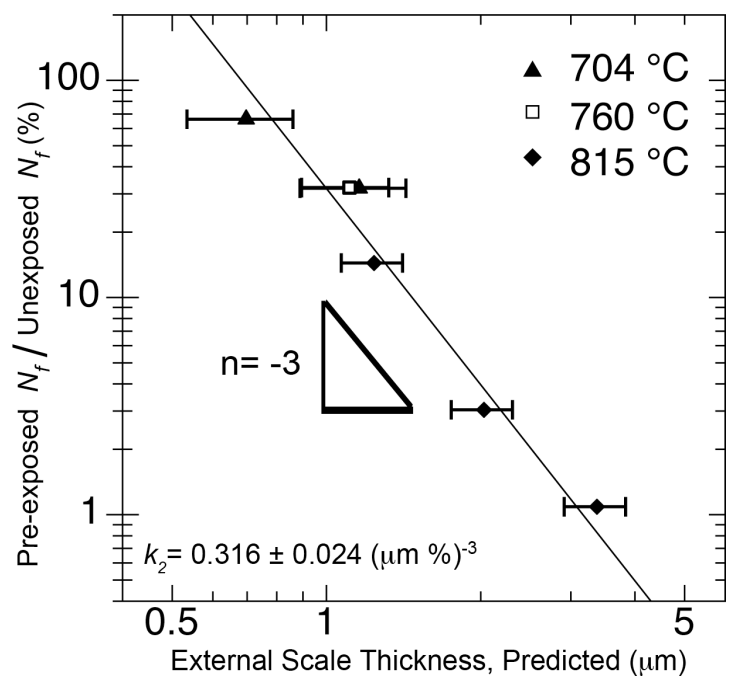

Fig 9. Normalized mean fatigue lives for pre-exposed specimens versus external oxide scale thickness, predicted by measured rate dependencies for ME3 static oxidation. The solid line denotes the power law fit, $y=\left(k_{2} \cdot t\right)^{n}$.

Specimens pre-exposed in vacuum at $815{ }^{\circ} \mathrm{C}$ for $440 \mathrm{~h}$ and machined blanks that were pre-exposed at $815{ }^{\circ} \mathrm{C}$ showed no debit in life, Fig. 8b. This confirms that the debits associated with prior exposures are due to environmental attack and any overaging of the microstructure by the pre-exposures does not significantly affect $N_{f}$. Removing the external oxide and oxide subscale from the notch (i.e., $20 \mu \mathrm{m}$ ) only showed marginal improvement in $N_{f}, 1,305$ vs. 489 cycles, for the $815^{\circ} \mathrm{C}$ for 2,020 $\mathrm{h}$ pre-exposure. However, material removal past the carbide dissolution layer yielded almost a full recovery in life, with $N_{f}$ of 32,980 cycles (i.e., $\sim 50 \mu \mathrm{m}$ )

The damage to the ME3 surfaces by the growth of an oxide layer likely influences the initial crack size, shape and distribution that govern the NLCF lives. The cumulative $N_{f}$ data for the various pre-exposures in air were normalized to the unexposed $N_{f}$ and plotted against the predicted external oxide scale thicknesses, Fig. 9. A log-log plot revealed a linear relationship that fit well to a simply power law of $n=-3$, which gave a $k_{2}=0.316 \pm 0.024(\mu \mathrm{m}$ $\%)^{-3}$. Coupling the cubic rate dependence of the oxide scale thickness, it follows that the percentage of fatigue life is proportional to (time) $)^{-1}$. This derived relationship predicts debits in fatigue life for oxide scale thicknesses that are greater than 0.68 $\pm 0.06 \mu \mathrm{m}$, which is roughly near the oxide scale thickness for the $704{ }^{\circ} \mathrm{C}$ for $440 \mathrm{~h}$ exposure.

\section{Effect of Prior Exposure on ME3 NLCF Failure Modes}

To discuss the failure modes with some clarity, it is helpful to group the air exposure conditions by: modest $\left(704{ }^{\circ} \mathrm{C}\right.$ for $100 \mathrm{~h}$, $704{ }^{\circ} \mathrm{C}$ for $440 \mathrm{~h}$ ), moderate $\left(704{ }^{\circ} \mathrm{C}\right.$ for $2,020 \mathrm{~h}, 760{ }^{\circ} \mathrm{C}$ for 440 h, $815^{\circ} \mathrm{C}$ for $100 \mathrm{~h}$ ), and aggressive $\left(815^{\circ} \mathrm{C}\right.$ for $440 \mathrm{~h}, 815^{\circ} \mathrm{C}$ for $2,020 \mathrm{~h}$ ) exposures. No debit in NLCF life was observed for the majority of the modest exposures, while there were measurable debits for both the moderate and aggressive exposures.

The number of major initiations sites observed for these NLCF tests is related to the degree of environmental damage. All failures initiated from the notch surfaces. Unexposed ME3

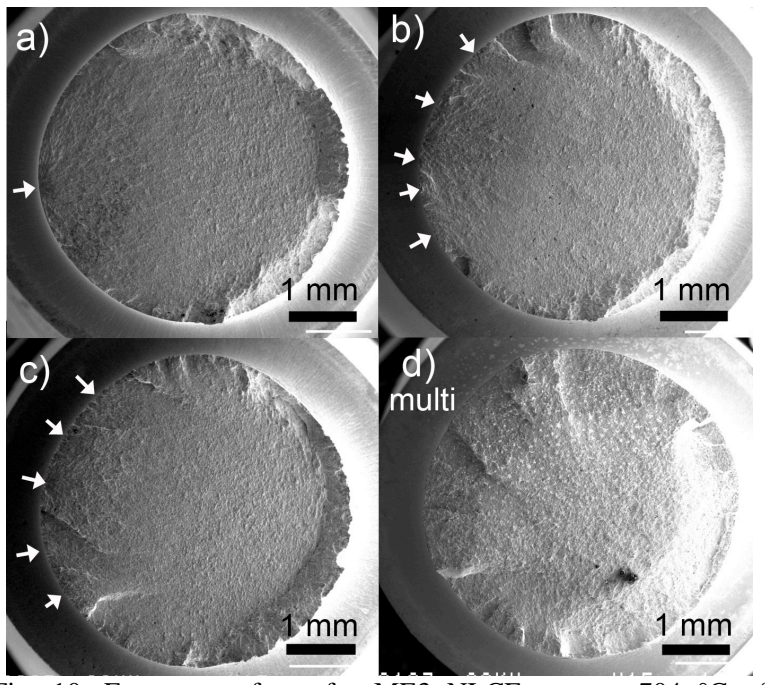

Fig. 10. Fracture surfaces for ME3 NLCF tests at $704{ }^{\circ} \mathrm{C}$ of specimens pre-exposed in air at: a) $704{ }^{\circ} \mathrm{C}$ for $100 \mathrm{~h}$, b) $704{ }^{\circ} \mathrm{C}$ for $2,020 \mathrm{~h}, \mathrm{c}) 815^{\circ} \mathrm{C}$ for $100 \mathrm{~h}$ and d) $815^{\circ} \mathrm{C}$ for $2,020 \mathrm{~h}$. Initiation sites are marked with white arrows.

specimens failed from a primary crack initiating and propagating transgranularly normal to the loading axis. For the representative fracture surfaces in Fig. 10, the major initiations for the modest and moderate exposures are marked with white arrows, while they are unmarked for the aggressive exposure, since there are many initiations (>15). For the modest exposures, Fig. 10a, specimens failed with either one or two primary initiations. The number of initiations sites clearly increases with exposure, Fig. 10a-d, which likely results from the increased thickness of the brittle oxide at the surface. For the moderate and aggressive exposures, Fig. 11 shows that notch surface oxide has multiple cracks normal to loading, which are located near the major crack initiation sites from the failed specimens. With thicker oxides, the loading conditions will produce a higher number of cracks within the oxide. For the various moderate exposures, the cracks varied in length from $10 \mu \mathrm{m}$ to $50 \mu \mathrm{m}$, while for the aggressive exposures the cracking is more extensive, with some cracks reaching $300 \mu \mathrm{m}$ in length due to crack propagation and coalescence during testing. More developed oxide cracks are ripe for major initiations, which is consistent with the observed increase in initiations with exposure.

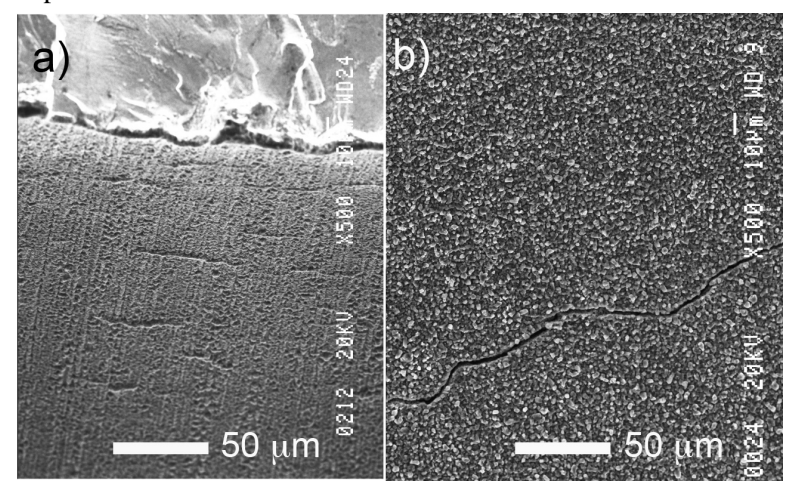

Fig. 11. From failed ME3 NLCF specimens exposed at a) $815^{\circ} \mathrm{C}$ for $100 \mathrm{~h}$ and b) $815{ }^{\circ} \mathrm{C}$ for $2,020 \mathrm{~h}$, these notch surfaces underneath a major crack initiation area show cracks within the oxide normal to the loading direction (approximately vertical). 
The surface failure initiation for the moderate exposures is ambiguous. Flat areas were often observed along the initiation ledge, which are consistent with the oxide cracks, Fig. 11a. It is plausible that these cracks coalesce and initiate failure. The surface failure initiation for an aggressively exposed specimen clearly follows the shape of the typical well-developed oxide

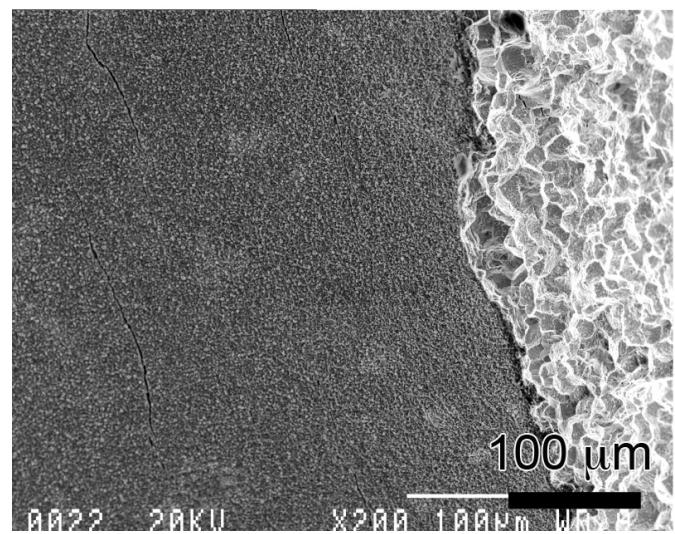

Fig.12. Surface failure initiation site (notch surface side view) observed for ME3 NLCF at $704{ }^{\circ} \mathrm{C}$ of a specimen pre-exposed in air at $815^{\circ} \mathrm{C}$ for $2,020 \mathrm{~h}$. Loading direction is horizontal.
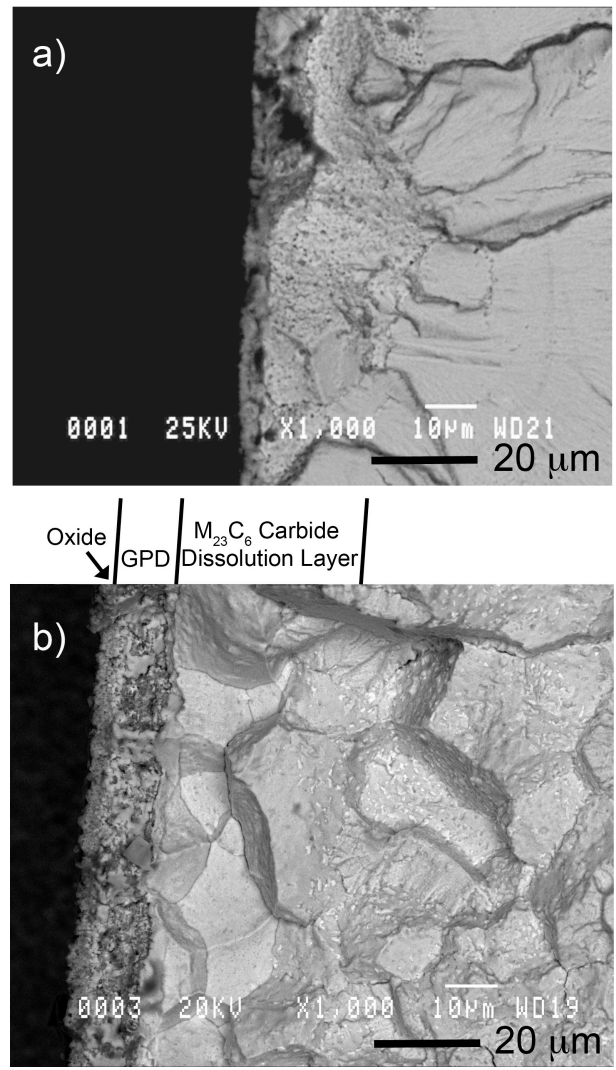

Fig. 13. Typical surface failure initiation sites (fracture surface view) observed for ME3 NLCF at $704{ }^{\circ} \mathrm{C}$ of specimens exposed in air at a) moderate exposures (ex. $815^{\circ} \mathrm{C}$ for $100 \mathrm{~h}$ ) and b) aggressive exposures (ex. $815^{\circ} \mathrm{C}$ for $2,020 \mathrm{~h}$ ). GPD denotes $\gamma^{\prime}$-dissolution layer.
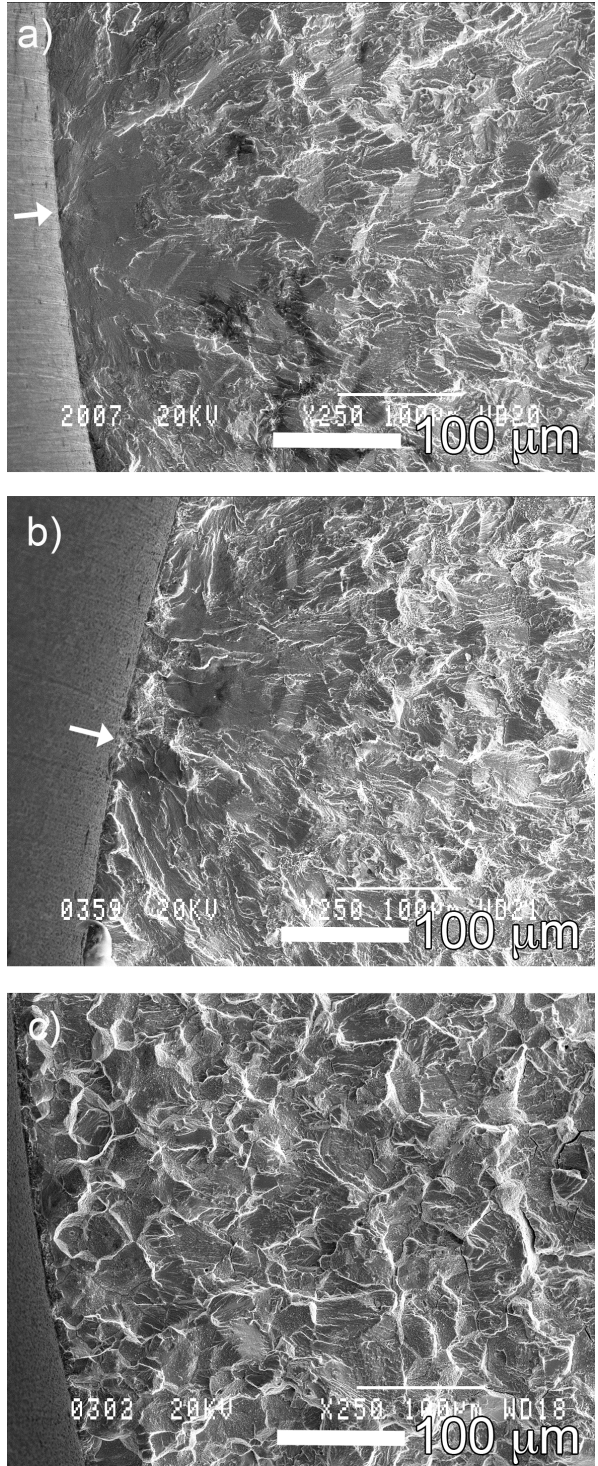

Fig. 14. Near surface crack propagation observed for ME3 NLCF tests at $704{ }^{\circ} \mathrm{C}$, for a) no to modest exposures (ex. $704{ }^{\circ} \mathrm{C}$ for 100 h), b) moderate exposures (ex. $704{ }^{\circ} \mathrm{C}$ for 2,020 h) and c) aggressive exposures (ex. $815^{\circ} \mathrm{C}$ for $440 \mathrm{~h}$ ).

crack, Fig. 12, indicating these specimens failed by cracks that initiated in the oxide scale. Furthermore, the short lives $(<1000$ cycles) as well as fractographic evaluation, Fig. 10d, suggests that the onset of the multi-initiations likely occurs within the first few cycles, and then fatigue life is primary consumed by propagation, and initiated coalescence of oxide cracks.

The fracture surface views of the typical surface failure initiation sites for the moderate and aggressive exposures are also shown in Fig. 13. Complimentary lower magnification images of the near surface crack propagation are shown in Fig. 14, including the failure modes often observed for the modest exposures: transgranular initiation and propagation normal to loading. For the failure initiation site for the moderate exposure, Fig. 13a, the 


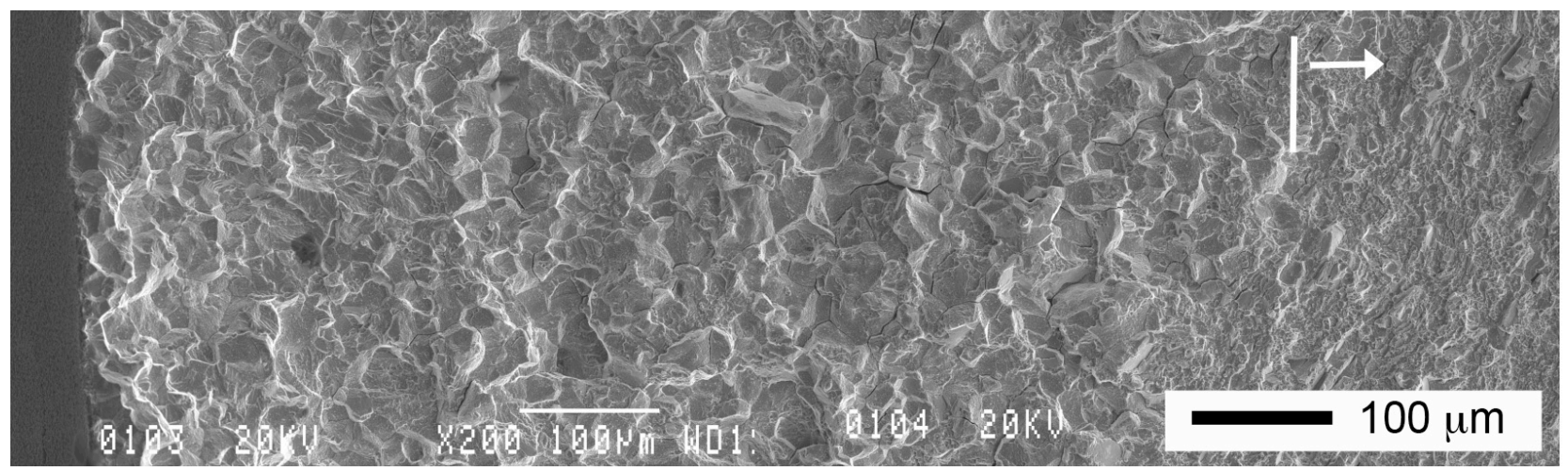

Fig. 15. White marker indicates the $810 \mu \mathrm{m}$ transition from intergranular propagation to transgranular overload for a notched fatigue specimen that received an $815^{\circ} \mathrm{C}$ for $440 \mathrm{~h}$ exposure prior to testing.

darker contrast volume at the surface, observed in back-scattered SEM image of Fig. 13a, is the external oxide and recystallized $\gamma$ ' dissolved layer (GPD). Together these layers are approximately 4 um thick. Environmental exposures cause the near surface grain boundaries to be degraded leading to early intergranular propagation that extends about one or two grains into the depth before transitioning to transgranular propagation, Fig. 13a and Fig. 14b. For the failure initiation site for an aggressive exposure displayed in Fig. 13b, the $\mathrm{M}_{23} \mathrm{C}_{6}$ carbides image as bright spots. It is clear that $\mathrm{M}_{23} \mathrm{C}_{6}$ carbides are dissolved through the first $\sim 50 \mu \mathrm{m}$ into depth. Despite this, intergranular propagation normal to the load for these specimens extended several hundred microns, reaching a full $1 \mathrm{~mm}$ for some cracks, Fig. 14c and Fig. 15. This indicates the ME3 grain boundaries beyond the carbide dissolution layer were also weakened by the exposures.

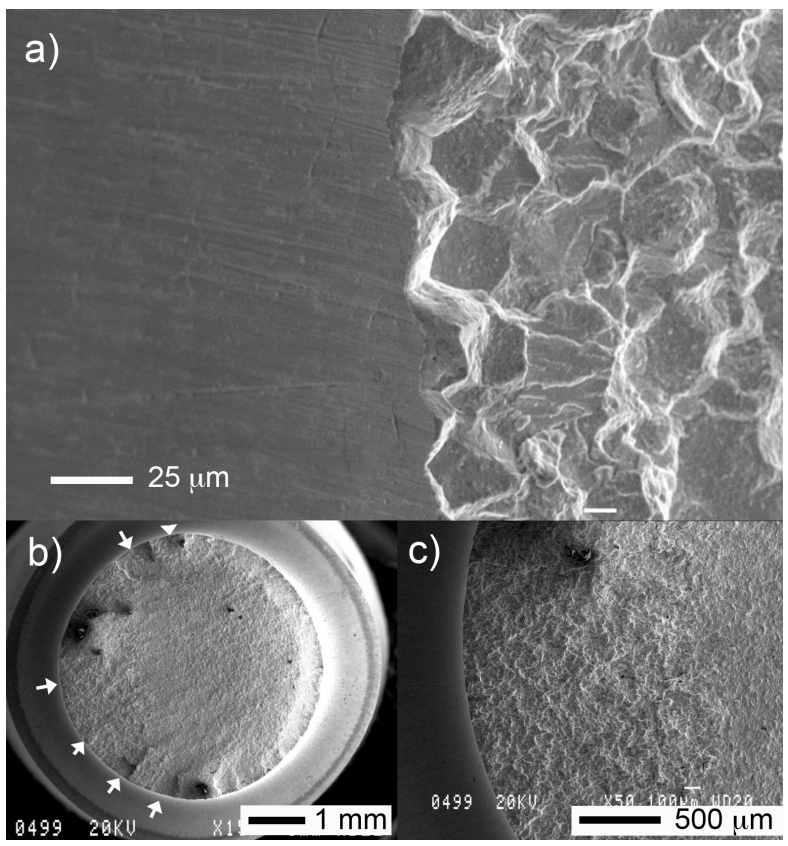

Fig. 16. Pre-exposed at $815^{\circ} \mathrm{C}$ for $2,020 \mathrm{~h}$, a specimen with the external oxide and oxide subscale removed ( $20 \mu \mathrm{m}$ from notch radius) shows: a) an intergranular initiation, b) multiple initiations and c) an intergranular propagation that extended $1490 \mu \mathrm{m}$.
The most aggressive exposure condition of $815^{\circ} \mathrm{C}$ for $2,020 \mathrm{~h}$ was used for layer removal experiments. As noted, the specimens that were aggressively exposed failed from cracks initiating at the environmental-affected surface layer with multiple initiations that propagated intergranularly normal to the loading axis. These exposed specimens had a mean NLCF life of 489 cycles. By removing the external and subscale oxides from the notch, yet leaving the carbide dissolution layer, the fatigue life only showed marginal improvement of 1,305 cycles. Fractographic evaluation revealed that the specimen failed by multiple intergranular initiations, where the cracks continued to propagate intergranularly normal to loading, Fig. 16. Intergranular propagation extended over $1 \mathrm{~mm}$ in distance before transitioning to transgranular overload, Fig. 16c, consistent with the specimens where no material was removed, Fig. 15. Surface initiations

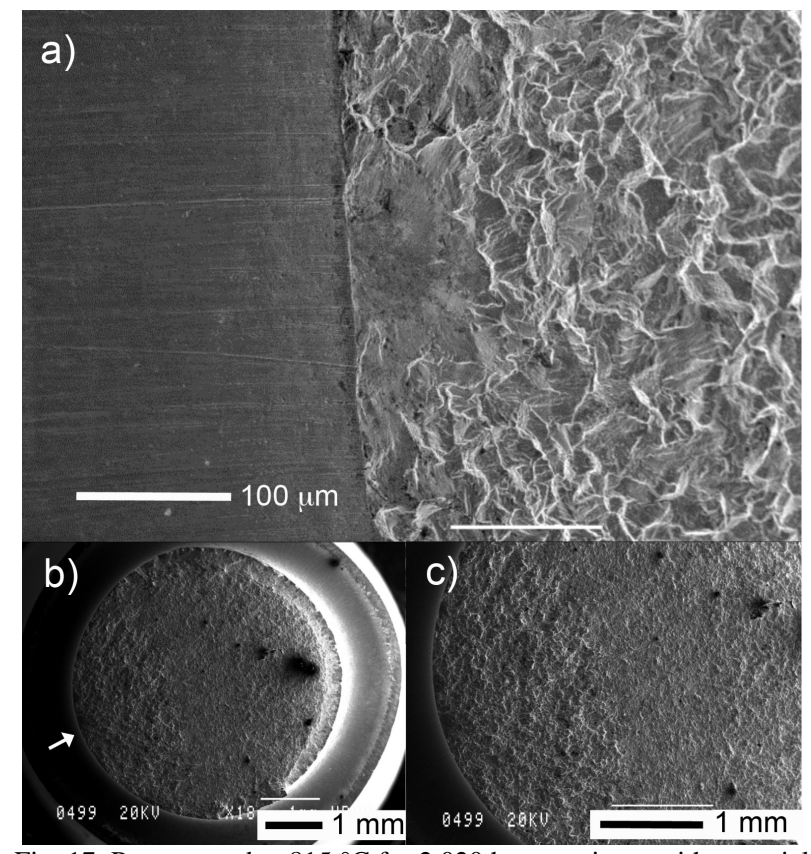

Fig. 17. Pre-exposed at $815{ }^{\circ} \mathrm{C}$ for $2,020 \mathrm{~h}$, a specimen with materia past the carbide dissolution layer removed $(\sim 50 \mu \mathrm{m}$ from notch radius) shows: a) a transgranular initiation, b) a single initiation and c) an intergranular propagation that extended $1570 \mu \mathrm{m}$. 
clearly fail by the weakened ME3 grain boundaries, where the $\mathrm{M}_{23} \mathrm{C}_{6}$ carbides had dissolved from the environmental exposure.

By removing material to below the $\mathrm{M}_{23} \mathrm{C}_{6}$ carbide dissolution layer, the weakest grain boundaries at the surface are removed. This removal condition gave a significant recovery in fatigue life of 35,998 cycles, which is nearly comparable to the fatigue life of 44,949 cycles for the unexposed specimens. Furthermore, the initiation observed is a single, transgranular initiation, Fig 17, which is typical of unexposed failures. However, not surprisingly the intergranular propagation extended over $1 \mathrm{~mm}$ in distance before transitioning to transgranular overload, Fig. 17c, which is consistent with all specimens exposed at $815^{\circ} \mathrm{C}$ for $2,020 \mathrm{~h}$.

\section{Summary and Conclusions}

Oxidation at potential maximum service temperatures over extended periods, and its effects on notched fatigue life for an advanced power metallurgy disk superalloy ME3 were investigated.

Supersolvus ME3 oxidizes like other high $\mathrm{Cr}$ containing disk superalloys. The near surface damage that results is complex. A continuous $\mathrm{Cr}_{2} \mathrm{O}_{3}$ scale forms, with faceted, superficial $\mathrm{TiO}_{2}$ grains at the exposed surface. Beneath the external scale, an internal subscale of branched $\mathrm{Al}_{2} \mathrm{O}_{3}$ extends into a layer where $\gamma$ 'precipitates have been dissolved by $\mathrm{Al}$ depletion. This $\gamma$ 'dissolution layer is recrystallized with finer grains and contains micron-sized voids at the grain boundaries. A semi-continuous ( $\mathrm{Ta}, \mathrm{Cr}) \mathrm{O}_{2}$ wets the interface between the $\mathrm{Cr}_{2} \mathrm{O}_{3}-\mathrm{TiO}_{2}$ scale and $\mathrm{Al}_{2} \mathrm{O}_{3}$ subscale. Throughout these layers and beyond, the $\mathrm{M}_{23} \mathrm{C}_{6}$ carbides have been dissolved from the original grain boundaries via grain boundary diffusion of $\mathrm{Cr}$ that helps support the $\mathrm{Cr}_{2} \mathrm{O}_{3}$ scale growth. The $\mathrm{Al}_{2} \mathrm{O}_{3}$ subscale growth follows the classic parabolic growth, however, the $\mathrm{Cr}_{2} \mathrm{O}_{3}-\mathrm{TiO}_{2}$ oxide scale deviates. The cubic rate dependence is attributed to grain growth in the external scale. The underlying difussional processes also lead to a cubic rate dependence for the $\gamma^{\prime}$-dissolution layer.

Prior exposure in air at $704^{\circ} \mathrm{C}, 760{ }^{\circ} \mathrm{C}$ and $815{ }^{\circ} \mathrm{C}$ significantly affected mean notched low cycle fatigue (NLCF) life. Mean NLCF fatigue life at $704{ }^{\circ} \mathrm{C}$ was measured from the average of 24 tests for each condition, where the majority of the conditions exhibited a scatter of about 2-4 times between low and high values. Reductions in NLCF fatigue life showed a power law decay with oxide scale thickness, suggesting that initial crack size, shape and distribution is correlated to the scale thickness. Experiments on aged material and vacuum exposures showed that environmental damage, not microstructural overaging, was driving the reduction in life. In addition, experiments on specimens with equivalent scale thicknesses from pre-exposures at the three isotherms had statistically equivalent fatigue lives, which demonstrates that fatigue debit is caused by surface damage not exposure temperature. No significant improvement in NLCF fatigue life was observed with the removal of the oxide scale and subscale, however a near full recovery was observed for specimens where material was removed past the $\mathrm{M}_{23} \mathrm{C}_{6}$ carbide dissolution layer. This indicated that grain boundary strength from the $\mathrm{M}_{23} \mathrm{C}_{6}$ carbides is important to the crack initiation for these tests. Despite material removal from the surface of these aggressively exposed specimens, the primary cracks propagated intergranularly, in contrast to the transgranular propagation typical for the unexposed specimens. This suggests the ME3 grain boundaries beyond the carbide dissolution layer were also weakened by the exposures. Further work is planned to determine the oxygen content at the grain boundaries.

\section{Acknowledgements}

The authors would like to acknowledge Dr. James Smialek (NASA-GRC), Brian Hazel (formerly of GE Aviation), Leah Underwood (GE Aviation) for technical discussion, as well as Jeff Marshman (Carl Zeiss) for focused-ion beam assistance. Support of the NASA Aviation Safety program, NASA Subsonic Fixed Wing program, and NASA Undergraduate Student Research Program is also acknowledged.

\section{References}

1. J.H. Chen, P.M. Rogers, and J.A. Little, "Oxidation Behavior of Several Chromia-Forming Commercial Nickel-Base Superalloys," Oxid Met, 47 (1997), 381-410.

2. A. Encinas-Oropesa, G.I. Drew, M.C. Hardy, A.J. Leggett, J.R. Nicholls, and N.J. Simms, "Effects of Oxidation and Hot Corrosion in a Nickel Disc Alloy," Superalloys 2008, ed. R.C. Reed, K.A. Green, P. Caron, T.P. Gabb, M.G. Fahrmann, E.S. Huron, and S.A. Woodard (Warrendale, PA: The Minerals, Metals \& Materials Society, 2008), 609-618.

3. A. Karabela, L.G. Zhao, J. Tong, N.J, Simms, J.R. Nicholls, and M.C. Hardy, "Effects of Cyclic Stress and Temperature on Oxidation Damage of a Nickel-Based Superalloy," Mater Sci Eng A, 528 (2011), 6194-6202.

4. T.P. Gabb, J. Telesman, P.T. Kantzos, J.W. Smith, and P.F. Browning, "Effects of High Temperature Exposures on Fatigue Life of Disk Superalloys," Superalloys 2004, ed. K.A. Green, T.M. Pollock, H. Harada, T.E. Howson, R.C. Reed, J.J. Schirra, and S. Walston (Warrendale, PA: The Minerals, Metals \& Materials Society, 2004), 269-274.

5. S.D. Antolovich, P. Domas, and J.L. Strudel, "Low Cycle Fatigue of René 80 as Affected by Prior Exposure," Met Trans A, 10A (1979), 1859-1868.

6. D.P. Mourer and J.L. Williams, "Dual Heat Treat Process Development for Advanced Disk Applications," Superalloys 2004, ed. K.A. Green, T.M. Pollock, H. Harada, T.E. Howson, R.C. Reed, J.J. Schirra, and S. Walston, (Warrendale, PA: The Minerals, Metals \& Materials Society, 2004), 401-408.

7. T.P. Gabb, A. Garg, D. L. Ellis, and K. O'Conner, "Detailed Microstructural Characterization of the Disk Alloy ME3" (NASA TM-2004-213066, National Aeronautics and Space Administration, Washington D.C., 2004).

8. T.P. Gabb, J. Telesman, P.T. Kantzos, and K. O'Conner, "Characterization of the Temperature Capabilities of Advanced Disk Alloy ME3," (NASA TM-2002-211796, National Aeronautics and Space Administration, Washington D.C., 2002).

9. M.J. Weimer, B.A. Nagaraj, J.C. Schaeffer, and J.A. Heaney (2003) "Pre-service Oxidation of Gas Turbine Disks and Seals," U.S. Pat. 6,532,657

10. G.A. Di Bari, "Nickel Plating," ASM Handbook, vol 5: Surface Engineering, ed. F. Reidenbach (Materials Park, OH: ASM International, 1994), 201-212.

11. T.P. Gabb, A. Garg, D.R. Miller, C.K. Sudbrack, D.R. Hull, D. Johnson, R. Rogers, J. Gayda, and L. Semiatin, "Formation of Minor Phases in a Nickel-based Superalloy" 
(NASA TM-2012-217604, National Aeronautics and Space Administration, Washington D.C., 2012).

12. D. Naumenko, B. Gleeson, E. Wessel, L. Singheiser, and W.J. Quadakkers, "Correlation between the Microstructure, Growth Mechanism, and Growth Kinetics of Alumina Scales on a FeCrAlY Alloy," Met Mater Trans A, 38A (2007), 2974-2983.

13. A. Atkinson, "Transport processes during the growth of oxide films at elevated temperature," Rev Modern Phys, 57 (1985), 437-470.

14. W.C. Hagel and A.U. Seybolt, "Cation Diffusion in $\mathrm{Cr}_{2} \mathrm{O}_{3}$," J Electrochem Soc, 108 (1961), 1146-1152. 